\title{
Partners of mutation-carriers for Huntington's disease: forgotten persons?
}

\author{
Marleen Decruyenaere ${ }^{1}$, Gerry Evers-Kiebooms ${ }^{1}$, Andrea Boogaerts ${ }^{1}$, Koen Demyttenaere ${ }^{2}$, \\ René Dom ${ }^{3}$ and Jean-Pierre Fryns ${ }^{4}$
}

\begin{abstract}
${ }^{1}$ Psychosocial Genetics Unit, University Hospital Gasthuisberg, University of Leuven, Leuven, Belgium; ${ }^{2}$ Department of Psychiatry, University Hospital Gasthuisberg, University of Leuven, Leuven, Belgium; ${ }^{3}$ Department of Neurology, University Hospital Gasthuisberg, University of Leuven, Leuven, Belgium; ${ }^{4}$ Center for Human Genetics, University Hospital Gasthuisberg, University of Leuven, Leuven, Belgium
\end{abstract}

This study focuses on psychological distress and coping strategies in partners of tested persons 5 years after predictive testing for Huntington's disease. A total of 16 carrier-couples and 17 noncarrier-couples participated in the study. Self-report questionnaires were used, assessing depression level, anxiety, intrusive and avoidance thoughts and coping strategies. Partners of carriers have as much distress as carriers, and for some distress variables even more $(P<0.05-0.001)$. They clearly experience more psychological distress than noncarriers' partners, as expected $(P<0.05-0.001)$. Regarding coping strategies, carriers' partners adopt more passive strategies (passive-regressive and avoiding reactions; $P<0.05$ ) and less active strategies (social support seeking and problem solving; $P<0.05-0.001$ ), compared to carriers. For both carriers and partners, the adoption of more passive strategies for coping was associated with more distress and the use of more active strategies with less distress (for carriers: $P<0.05-0.001$; for carriers' partners: $P<0.05$ ). The presence of children before predictive testing was an additional result-specific distress factor in carriers and their partners. In conclusion, carriers' partners have at least as much psychological distress as carriers, but partners have the tendency to draw back. The results suggest that the grief of carriers' partners may be 'disenfranchised', or not socially recognised, as if they have no right to mourn. We moreover interpreted the results referring to concepts such as anticipatory grief, psychological defences, dissonance processes and imbalanced partner relationship. Finally, we formulated some implications for genetic counselling.

European Journal of Human Genetics (2005) 13, 1077-1085. doi:10.1038/sj.ejhg.5201462;

published online 6 July 2005

Keywords: Huntington's disease; partners; predictive testing; psychological impact; disenfranchised grief

\section{Introduction}

The impact of predictive testing for Huntington's disease (HD) on psychological functioning of tested persons has been extensively described. The earlier studies, covering a follow-up period of some months to 3 years after testing, ${ }^{1-6}$ reported that about $10-15 \%$ of both carriers and non-

Correspondence: Dr M Decruyenaere, Psychosocial Genetics Unit, Center for Human Genetics, Herestraat 49, B-3000 Leuven, Belgium.

Tel: 32163458 74; Fax: 32163460 51;

E-mail: marleen.decruyenaere@uz.kuleuven.ac.be

Received 16 February 2005; revised 30 May 2005; accepted 1 June 2005; published online 6 July 2005 carriers reported psychological problems after testing, including psychological burden, a period of depression, hopelessness about the future, concern about the children or (survivor) guilt. The lower-than-expected rate of problems in carriers was attributed ${ }^{1-6}$ to the pre- and post-test psychological counselling, the self-selection of the participants, which is associated with mental resourcefulness and their coping strategies to deal with the test result. However, more recent studies ${ }^{7-10}$ showed that psychological distress after testing should not be underestimated. Almqvist et al found that, 5 years after testing, about $25 \%$ of the carriers had scores in the clinical depression range. Decruyenaere 
et $a l^{8}$ also reported that psychological distress reappeared or remained high after testing in about $25 \%$ of the tested persons: those who asked for the test because they could not live with the uncertainty, without being able to specify concrete actions after the test, were significantly more distressed than those who wanted the test for specified aims. Codori et $a l^{9}$ mentioned a 1-year prevalence of clinically significant depressive symptoms of $20 \%$ in carriers. The higher rate of psychological problems, compared to previous studies, was ascribed to the assessment method: psychiatric interviews. Timman et al ${ }^{10}$ found that carriers became more hopeless $7-10$ years after testing compared to baseline, while intrusive and avoidance thoughts gradually became less frequent in the long term. The increased feelings of hopelessness were explained by the approaching age of onset, the onset of HD in relatives, loss experiences and the possible occurrence of subtle symptoms in some carriers.

Psychological functioning in partners of tested persons received less attention. Qualitative data ${ }^{11,12}$ showed that partners of carriers were pessimistic about the future and were more depressed by the positive test result than were carriers. Some felt the need to talk to professionals but were reluctant to seek social support. Follow-up studies with psychometric testing ${ }^{5,10,13}$ demonstrated that partners of carriers showed a similar course of distress as carriers. The presence of children before testing and older age were associated with more distress in partners of carriers. Compared with non-carriers' partners, carriers' partners had higher levels of psychological distress.

The present study focused on psychological distress and coping strategies in partners of tested persons 5 years after testing. Comparisons with tested persons were made. Based on the above-mentioned literature on partners, we tested two hypotheses. The first one was that carriers' partners have as much distress as carriers and that they are more distressed than noncarriers' partners. The second hypothesis was that carriers' partners seek less social support than carriers and this may be linked with more psychological distress. A third hypothesis was based on findings in health psychology. Several studies ${ }^{14-16}$ have shown that an active, task-oriented strategy of coping, in which patients tackle problems, remain optimistic and seek attention and care, is associated with less distress and better quality of life. A passive coping strategy with resignation, withdrawal, avoidance and ruminations is associated with more distress. Therefore, we expected that more distress would be associated with less active problem solving, less comforting ideas, less social support seeking and with more passive-regressive and avoiding reactions.

\section{Methods}

In Leuven (Belgium), predictive testing for HD has been available as a clinical service within a multidisciplinary context ${ }^{17}$ since November 1987. Follow-up counselling has been systematically offered at 1 week (for carriers), 1 month, 1 year and 5 years post-test. If necessary, additional counselling is available. In 1993, we started with the 5-year follow-up, combining counselling with psychological research. ${ }^{8}$ The 5 -year study is an extensive psychological assessment of tested persons and their partners. Participants were informed about the study; they agreed that the interview data and the questionnaires would be used for research purposes. Two members of the regular HD-team counselled and interviewed the tested person and the partner, partly together, partly separately.

\section{Measures}

Level of depression: We used the Beck Depression Inventory $^{18,19}$ to assess depression level.

General and specific anxiety: The Spielberger's State Trait Anxiety Inventory ${ }^{20,21}$ (STAI) was used to measure traitand state-anxiety.

Intrusion and avoidance: The degree of subjective impact of HD was measured with the Impact of Event Scale ${ }^{22}$ (IES). The IES consists of two scales: intrusion (intrusively experienced ideas, feelings and thoughts about HD; seven items; score range: 0-35), and avoidance (consciously avoiding HD-related ideas, feelings and situations; eight items; score range: $0-40$ ).

Result-specific feelings: The Health Orientation Scale ${ }^{23}$ (HOS) was used to assess the feelings associated with the test result. It consists of 12 bipolar five-point scales (bad-good, afraid-not afraid, guilty-not guilty, ashamed-unashamed, weak-strong, shocked-relieved, sad-happy, marked-unmarked, incompetent-competent, angrypleased, passive-active, sick-healthy). The HOS randomly presents the positive or the negative pole at the right. Score range: $12-60$.

Coping strategy: The Utrechtse Coping List $^{24,25}$ assesses seven coping strategies: active problem solving (seven items), palliative coping (8), avoiding reactions (8), social support seeking (6), passive-regressive coping (7), expression of emotions (3) and comforting ideas (5). We asked the carrier-couples how they cope with the positive test result on a 4-point scale.

The Avoidance- and the Intrusion-scale of the IES and the BDI were not normally distributed. Therefore, raw scores of these three scales were square root transformed.

\section{Participants}

In the period between November 1987 and November 1998, 126 Flemish-speaking individuals with an affected parent had received a test result (46 carriers, 79 noncarriers, one equivocal result). In November 1993, we started with the 5-year follow-up counselling of these persons and their partners. They were also invited to participate in the follow-up study. Given the larger proportion of non- 
carriers, we decided to end the data-collection in noncarriers in November 1999. The person with the equivocal result was not included in the study.

Carrier-couples: In all, 29 of the 46 carriers participated in the study (63\% response rate in carriers). Most important reasons for nonparticipation of carriers were: having symptoms, no need for follow-up counselling and no correct contact address. At baseline, 26 of these 29 participating carriers had a partner. Five years post-test however, seven couples were separated. ${ }^{26}$ In all, 16 partners of the remaining 19 couples participated in the study. During the follow-up contact, the interviewers had doubts about possible symptoms in five carriers (probable minimal signs, no certainty, no neurological examination). One of the five carriers and two partners were also concerned about possible symptoms.

Noncarrier couples: In all, 33 of the 43 eligible noncarriers participated in the study $(77 \%$ response rate in noncarriers). Most nonparticipation was due to lack of interest in follow-up counselling. At baseline, 26 of these 33 noncarriers had a partner. Five years post-test, six couples were separated. $^{26}$ In total, 17 partners of the remaining 20 couples participated in the 5-year follow-up study.

The analyses of distress and coping strategies in the present study were based on data of couples in which the tested person and the partner both participated in the 5 -year study.

\section{Results}

\section{Baseline characteristics}

Socio-demographic characteristics: In order to test whether the couples in which both partners participated in the 5-year study differed at baseline from the couples in which only the tested person participated in the follow-up study, we compared their baseline socio-demographic characteristics (Table 1). We found no significant differences.

Psychological characteristics: Table 2 presents baseline psychological characteristics for the tested persons who participated in the 5-year follow-up study. Unfortunately, we have no information on the partner's pretest psychological functioning. We compared the tested persons whose partner participated in the study with those whose partner did not participate and we found no significant differences. Drop-out group: We, moreover, inspected whether the group of tested persons lost at the 5-year follow-up differed from the participants in the study with regard to baseline sociodemographic data and psychological characteristics. ${ }^{8}$ No significant differences were found, not for the total group, nor for carriers and noncarriers separately.

\section{Psychological distress in tested couples, 5 years after testing}

Table 3 presents the means for the distress measures, 5 years after testing. These results are based on data of

Table 1 Baseline socio-demographic characteristics

\begin{tabular}{|c|c|c|c|c|}
\hline & \multicolumn{2}{|c|}{$\begin{array}{c}\text { Couples in which both partners participated in } \\
\text { the 5-year contact }\end{array}$} & \multicolumn{2}{|c|}{$\begin{array}{l}\text { Couples in which only the tested person } \\
\text { participated in the 5-year contact }\end{array}$} \\
\hline & $\begin{array}{l}\text { Carrier couples } \\
\quad(N=16)\end{array}$ & $\begin{array}{l}\text { Noncarrier-couples } \\
\quad(N=17)\end{array}$ & $\begin{array}{l}\text { Carrier couples } \\
\quad(N=10)\end{array}$ & $\begin{array}{l}\text { Noncarrier-couples } \\
\qquad(N=9)\end{array}$ \\
\hline \multicolumn{5}{|l|}{ Sex of the tested persons } \\
\hline Men & $7(44 \%)$ & $5(29 \%)$ & $5(50 \%)$ & \\
\hline Women & $9(56 \%)$ & $12(71 \%)$ & $5(50 \%)$ & $9(100 \%)$ \\
\hline \multicolumn{5}{|c|}{ Age at baseline: Mean (SD) } \\
\hline of the tested persons & $32.2(7.2)$ & $36.9(9.1)$ & $31.6(9.5)$ & $30.3(7.3)$ \\
\hline of the partners & $32.9(8.8)$ & $36.6(10.1)$ & $33.9(10.4)$ & $33.1(6.5)$ \\
\hline \multicolumn{5}{|c|}{ Educational level of tested persons } \\
\hline$<$ High school & & $2(12 \%)$ & & \\
\hline High school & $11(69 \%)$ & $9(53 \%)$ & $7(70 \%)$ & $7(78 \%)$ \\
\hline$>$ High School & $5(31 \%)$ & $6(35 \%)$ & $3(30 \%)$ & $2(22 \%)$ \\
\hline \multicolumn{5}{|c|}{ Educational level of partners } \\
\hline$<$ High school & $1(6 \%)$ & $1(6 \%)$ & $1(10 \%)$ & $1(11 \%)$ \\
\hline High school & $10(62 \%)$ & $14(82 \%)$ & $8(80 \%)$ & $6(67 \%)$ \\
\hline$>$ High School & $5(31 \%)$ & $2(12 \%)$ & $1(10 \%)$ & $2(22 \%)$ \\
\hline \multicolumn{5}{|l|}{ Number of children } \\
\hline No children & $9(56 \%)$ & $4(24 \%)$ & $6(60 \%)$ & $4(44 \%)$ \\
\hline 1 child & $3(19 \%)$ & $5(29 \%)$ & $2(20 \%)$ & $1(11 \%)$ \\
\hline$>1$ child & $4(25 \%)$ & $8(47 \%)$ & $2(20 \%)$ & $4(44 \%)$ \\
\hline
\end{tabular}

Comparison of couples in which both partners participated in the follow-up study $(N=33)$ with couples in which only the tested person participated in the follow-up study $(n=19)$. 
Table 2 Baseline psychological characteristics of tested persons

\begin{tabular}{|c|c|c|c|c|}
\hline \multirow[t]{2}{*}{ Variables : Mean (SD) } & \multicolumn{2}{|c|}{$\begin{array}{l}\text { Participants whose partner also participated in the } 5 \text { - } \\
\text { year study }(n=33)\end{array}$} & \multicolumn{2}{|c|}{$\begin{array}{c}\text { Participants whose partner did not participate in } \\
\text { the 5-year study }(n=19)\end{array}$} \\
\hline & Carriers $(N=16)$ & Noncarriers $(N=17)$ & Carriers $(N=10)$ & Noncarriers $(N=9)$ \\
\hline
\end{tabular}

Comparison of those whose partner also participated in the follow-up study $(n=33)$ with those whose partner did not participate in the follow-up study $(n=19)$.

Table 3 Psychological distress in tested persons and their partners, 5 years after predictive testing (33 couples)

\begin{tabular}{|c|c|c|c|c|c|c|c|c|}
\hline \multirow[b]{2}{*}{$\begin{array}{l}\text { Variables: Mean } \\
(S D)\end{array}$} & \multicolumn{3}{|c|}{ Carrier-couples Mean (SD) } & \multicolumn{2}{|c|}{ Noncarrier-couples Mean (SD) } & \multirow[b]{2}{*}{$t$-test $t^{a}$} & \multirow{2}{*}{$\begin{array}{c}\text { t-test: } \\
\text { Carriers vs } \\
\text { Noncarriers }^{\mathrm{b}}\end{array}$} & \multirow{2}{*}{$\begin{array}{c}\text { t-test: C } \\
\text { partners vs } \\
\text { NC partners }\end{array}$} \\
\hline & $\begin{array}{l}\text { Carriers } \\
(N=16)\end{array}$ & $\begin{array}{l}\text { Partners } \\
(N=16)\end{array}$ & $t$-test $t^{a}$ & $\begin{array}{c}\text { Noncarriers } \\
(N=17)\end{array}$ & $\begin{array}{l}\text { Partners } \\
(N=17)\end{array}$ & & & \\
\hline Depression (BDI) & $2.2(3.8)$ & $4.4(4.7)$ & NS & $4.3(5.3)$ & $2.8(3.3)$ & NS & NS & NS \\
\hline $\begin{array}{l}\text { General Anxiety } \\
\text { (STAl-Trait) }\end{array}$ & $35.1(10.3)$ & $40.7(7.1)$ & 0.02 & $34.3(9.2)$ & $32.4(8.9)$ & NS & NS & 0.006 \\
\hline Intrusion (IES) & $8.7(6.9)$ & $10.7(7.1)$ & NS & $8.8(9.1)$ & $4.9(5.0)$ & NS & NS & 0.04 \\
\hline Avoidance (IES) & $10.4(7.8)$ & $13.7(8.1)$ & NS & $5.3(7.2)$ & $5.0(4.9)$ & NS & 0.04 & 0.0008 \\
\hline $\begin{array}{l}\text { Result-sp. } \\
\text { feelings (HOS) }\end{array}$ & $46.8(7.3)$ & $36.9(6.9)$ & 0.0004 & $54.6(3.1)$ & $57.1(3.3)$ & 0.02 & 0.0003 & $<0.0001$ \\
\hline
\end{tabular}

HOS: Health orientation scale: higher scores mean more positive feelings.

${ }^{a}$ Test of differences between tested persons and partners: $t$-test for dependent samples.

${ }^{\mathrm{b}}$ Test of differences between carriers and noncarriers: $t$-test for independent samples.

${ }^{\mathrm{C}}$ Test of differences between carriers-partners and noncarrier-partners: $t$-test for independent samples.

NS: not significant.

couples in which both the tested person and the partner participated in the 5-year-follow-up (16 carrier-couples and 17 noncarrier-couples). Compared to carriers, partners of carriers had significantly more general anxiety $(P<0.01)$ and more negative feelings about the test result $(P<0.001)$. Within noncarrier-couples, partners had significantly more positive feelings about the test result than noncarriers $(P<0.05)$. The largest differences were found between carriers' partners and noncarriers' partners. Overall, noncarriers' partners had the least trait- and state-anxiety, intrusive and avoidance thoughts and had the most positive feelings about the test result.

We investigated whether psychological distress after testing in carrier-couples was associated with having children at baseline and whether this association was different for carriers and partners (repeated measures analyses). A significant association was only found for result-specific emotions (HOS). Carriers and partners who had children before the test reported significantly more negative feelings about their test result $(\mathrm{HOS}-$ mean $=39.0$; $\mathrm{SD}=7.6 ; 7$ couples) than carriers and partners who had no children before the test $(\mathrm{HOS}-$ mean $=44.1$; $\mathrm{SD}=8.9$; nine couples) $(F=4.50 ; P<0.05)$. Note that lower HOS-scores indicate more negative feelings. The analysis showed no significant interaction effect on distress of having children and being a carrier/carrier's partner.

Psychological distress scores were not significantly associated with age. Additionally, we checked whether the partners of possibly affected carriers $(N=5)$ differed from the group of partners of carriers without symptoms. The differences in psychological distress were not significant.

In order to get more information on result-specific feelings (HOS), we explored this scale in more detail (Figure 1). Except for feelings of guilt, partners of carriers clearly have the most negative feelings about the test result. Compared to carriers, they feel significantly worse, more afraid, more shocked, sadder, less competent, angrier and more passive when considering the test result. The profile of noncarriers' partners is located at the positive side of the scales and overlaps for most items with that of the noncarriers.

As mentioned above, an association of result-specific emotions with having children was found in carriercouples. Therefore, we explored for which specific emo- 


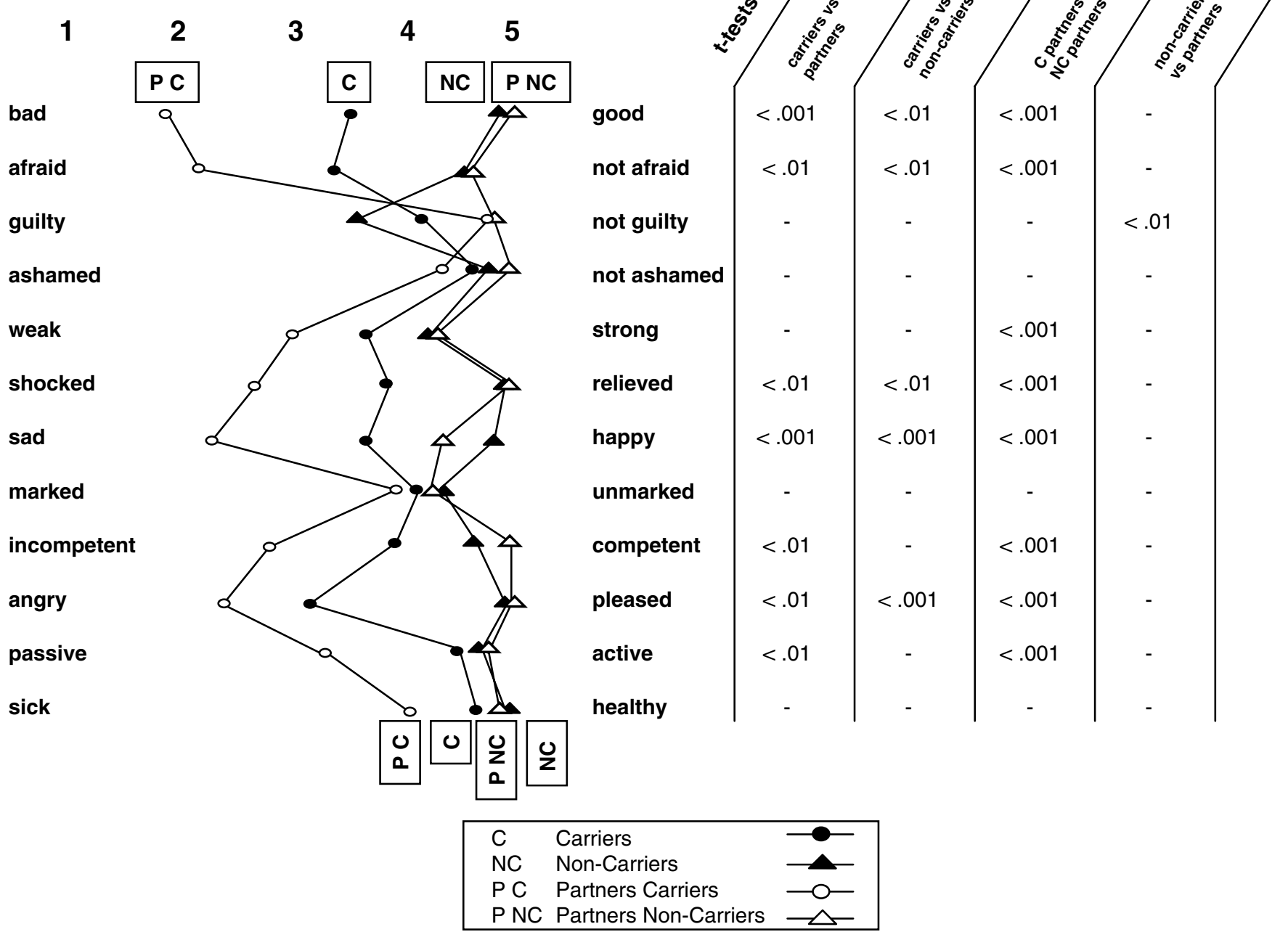

Figure 1 Mean scores for Health Orientation Scales (HOS).

tions those with children differed significantly from those without children and we tested whether these differences were the same for carriers and partners (repeated measures analyses). We found a significant difference for guilt (item 3). Carriers with children reported that they felt significantly guiltier $(P<0.01)$ than carriers without children; this difference was not significant in the group of carriers' partners.

\section{Coping strategies and psychological distress in} carrier-couples

During the 5-year study, carrier-couples were also asked how they cope with the test result (Table 4). Compared to carriers, carriers' partners use significantly less social support seeking, more avoidance, more passive-regressive coping and less active problem solving.
Table 5 presents Pearson correlation coefficients between distress and coping. For carriers, active problem solving was associated with less distress and passive-regressive coping with more distress. The same holds for the total group of subjects ( $n=32$; not in table). The correlations between these two strategies and distress are much lower in the group of partners (Table 5). In this group, avoidance was associated with more distress and social support seeking with less distress.

\section{Discussion}

Common sense might expect that mutation carriers, facing a debilitating disease, a frightening future and an untimely death, would suffer the highest distress levels, followed by the carriers' partners, who themselves will not develop HD 
Table 4 Coping strategies in carrier-couples, 5 years after testing (Mean item scores: range 1-4)

\begin{tabular}{|c|c|c|c|c|c|}
\hline \multirow{2}{*}{$\begin{array}{l}\text { Utrechtse coping list } \\
\text { Strategies (number of items) }\end{array}$} & \multicolumn{2}{|c|}{ Carriers $N=16$} & \multicolumn{2}{|c|}{ Partners $N=16$} & \multirow[t]{2}{*}{$P^{*}$} \\
\hline & Mean & $S D$ & Mean & $S D$ & \\
\hline Active problem solving $^{\mathrm{d}}(7)$ & $2.9^{a}$ & 0.78 & 2.4 & 0.38 & 0.04 \\
\hline Palliative coping (8) & 2.0 & 0.44 & 1.9 & 0.47 & NS \\
\hline Avoidance (8) & 1.7 & 0.37 & 2.0 & 0.32 & 0.02 \\
\hline Social support seeking (6) & $2.4^{\mathrm{b}}$ & 0.65 & 1.7 & 0.47 & 0.0004 \\
\hline Passive-regressive coping (7) & 1.3 & 0.42 & 1.7 & 0.38 & 0.04 \\
\hline Expression of emotions (3) & 1.7 & 0.36 & $1.6^{\mathrm{c}}$ & 0.44 & NS \\
\hline Comforting ideas (5) & 2.4 & 0.47 & 2.3 & 0.33 & NS \\
\hline
\end{tabular}

${ }^{*} t$-tests for differences between carriers and partners (dependent samples).

Tests for difference with general population means:

${ }^{\text {a }}$ Significantly higher than the norm group of the UCL $(P<0.05)$.

${ }^{b}$ Significantly higher than the norm group of the UCL $(P<0.01)$.

'Significantly lower than the norm group of the UCL $(P<0.01)$.

dSignificant difference between the variances $(P<0.001)$.

NS: not significant.

Table 5 Correlations between psychological distress and coping strategies in carriers $(N=16)$ and carriers' partners $(N=16)$

\begin{tabular}{|c|c|c|c|c|c|c|}
\hline & $B D I$ & Trait & State & Intrus & Avoid & Result-specific emotions $s^{\mathrm{a}}$ \\
\hline Active problem solving & $-0.62^{* *}$ & $-0.65^{\star *}$ & $-0.87^{* * *}$ & -0.36 & -0.28 & $0.64^{* *}$ \\
\hline Social support & & & -0.31 & & & 0.47 \\
\hline Passive-regr coping & 0.34 & $0.74^{\star *}$ & $0.62^{* *}$ & $0.78^{* *}$ & $0.68^{* *}$ & $-0.72^{\star *}$ \\
\hline Avoidance & $0.53^{*}$ & $0.49^{*}$ & 0.45 & 0.29 & 0.46 & \\
\hline Social support & & -0.42 & -0.29 & & -0.43 & 0.51 * \\
\hline Passive-regr coping & 0.45 & $0.56^{\star}$ & & 0.32 & & $-0.51^{\star}$ \\
\hline
\end{tabular}

Only correlations $>0.25$ are mentioned.

${ }^{a}$ HOS: Health orientation scale: higher scores mean more positive feelings.

${ }^{\star} P<0.05,{ }^{* *} P<0.01,{ }^{* *} P<0.001$.

but will care for their affected partner in the future and will eventually suffer the loss of their partner. However, some studies $^{11,12}$ have reported that carriers' partners have more - or at least as much - psychological difficulties adapting to the positive test result, compared to carriers. The present study confirms that carriers' partners have as much distress as carriers, and for some assessments even more (hypothesis 1). When considering the test result, carriers' partners felt significantly worse, more afraid, more shocked, sadder, less competent, angrier and more passive, compared to carriers. Carriers' partners also reported more psychological distress than noncarriers' partners, as expected. Several psychological mechanisms may play a part in explaining the findings in the carriers and their partner. First of all, it is possible that the main attention after testing is focused on carriers and that partners receive less consideration, not only by relatives and friends, but also by health professionals. It is indeed likely that carriers' partners are 'forgotten persons' compared to carriers, just like patients' partners compared to patients. ${ }^{27-29}$ Our study, moreover, showed that, overall, carriers' partners seek less social support than carriers (hypothesis 2). Lower social support seeking was associated with more negative feelings about the test result in partners. The partners' lower support seeking may be rooted in their concern not to upset or burden the mutation-carrier.

Sobel and Cowan ${ }^{12,30}$ described the multiple and cumulative losses that families experience after predictive testing and showed that a positive test result produced an ambiguous loss, that is a loss that is incomplete or uncertain. The asymptomatic carrier is not sick, but has become 'the apparently well'. Although the loss has not yet occurred, a positive test result makes it imminent. An ambiguous loss induces disenfranchised or unacknowledged grief: ${ }^{30}$ 'a grief about a loss that is not or cannot be openly acknowledged, publicly mourned or socially 
supported', thus as if they have no right to mourn. The partner's current loss may be considered even more ambiguous and thus less socially recognised than the carrier's loss, which may lead to withdrawal and to a magnification of the negative feelings in the partner. ${ }^{30}$ This may explain the reported findings on lower social support seeking and higher result-specific distress in partners.

The kind of coping strategies used may be another possible explanation: carriers' partners may adopt other coping strategies than carriers and this may be linked to psychological distress (hypothesis 3). The results indeed confirmed that, compared to carriers, carriers' partners not only sought significantly less social support, but also utilised less active problem solving and more passiveregressive and avoiding behaviour. In the group of carriers, active problem solving was associated with less distress and passive-regressive reactions with more distress. These correlations were lower for partners. For partners, moreover, avoiding reactions tend to be associated with more psychological distress and seeking social support with less distress. Further research on larger samples of carriercouples is needed to confirm these findings. In any case, it is clear that the association between coping and psychological distress is complex. A reciprocal relationship is highly plausible: coping has an impact on distress and distress influences coping strategies. ${ }^{15}$ Moreover, distress and coping strategies may be influenced by other variables, such as personal strength or resilience.

Denial is a concept often encountered to explain psychological responses to stressful events. ${ }^{31}$ It is possible that carriers' partners use less denial, compared to carriers. Denial is an unconscious psychological defence mechanism, activated by psychological self-protection and more frequently used as the threat becomes more personally relevant. The difference with the concept avoidance, as used in the present study, is that avoidance refers to consciously avoiding HD-related thougths and situations. In an unalterable, threatening situation, denial can be regarded as an adaptive emotion-focused coping mechanism because it may afford relief, comfort and positive thinking. Denial can also be maladaptive because it may prevent adjustment to and integration of the problem in daily life and thus maintain psychological distress. Denial is, however, mostly unconscious and therefore difficult to assess. Our study does not allow ascertaining the role of denial in psychological distress. In order to achieve clarification of the role of psychological defences, in-depth studies with refined assessment methods are needed.

Genetic counselling guidelines generally stress that it is the person at risk for HD who must make the ultimate decision regarding whether or not to proceed with predictive testing. According to dissonance theory, ${ }^{32,33}$ individuals tend to minimise the perceived harm arising from personal choices because they want to justify these choices. Thus, the free choice to proceed with predictive testing may contribute to a minimisation of perceived harm by carriers. The partner of the carrier, however, may feel he/she had less choice in the decision on testing and thus may be less in need of distress minimisation after an unfavourable test result. This may be another hypothesis to explain the distress levels found in carriers and their partners.

An imbalance in the partner relationship may be an extra element of distress in the group of carriers' partners. Qualitative data on the post-test partner relationship ${ }^{26}$ showed an imbalance in take-and-give in some relationships: some carriers' partners have the tendency to take up too much care and responsibilites before the onset of HD. However, the partner's own frustrated needs may trouble him/her, inducing more negative feelings about the test result. The partners' caregiving attitude may originate from their wish to be supportive and loyal. It may also be an answer to the carriers' appeal for care and support or the partner may consider it as an obligation from which he/she cannot escape.

Psychological distress in carrier-couples can be interpreted as manifestations of a mourning process, where anticipated loss plays a central role. ${ }^{12,30}$ Not only mutation carriers but also their partners have lost a 'normal' future: they face a burdening future in which the negative impact of the disease on their own and their spouse's life, on the partner relationship and on the children will eventually only grow. In our study, carriers and their partners who had children before the test reported significantly more negative feelings about their test result at the 5-year contact than those who had no children before the test. It is clear that having children who are at risk for HD is an important stress factor for parents in HD families. ${ }^{5,12,30}$ Carrier-couples face the difficult task of telling their offspring about their risk status and helping them to cope with it. The partner will not only (have to) take care of the carrier in the future, it is, moreover, likely that he/she will also witness the disease in some of the children. Guilt feelings about passing the mutation to the children may play a significant part in the negative emotions in the parents. According to our data carriers felt more guilty when having children at risk for HD.

Bloch et $\mathrm{al}^{34}$ described an interesting model of carriers' psychological responses to the clinical manifestation and diagnosis of HD. Little is known about the psychological reactions of carriers' partners when the first symptoms appear. We found no significant differences between partners of possibly affected carriers and partners of other carriers. However, it is clear that the sample was too small to ascertain the effect of the disease onset on the course of distress. Moreover, since this was not the aim of our study, we did not include a neurological examination to confirm the presence of first symptoms.

In this study, we presented information on couples in which both the tested person and their partner participated 
in the 5-year follow-up study. We have no information on ex-partners, new partners and couples who did not participate in the follow-up study. Timman et al ${ }^{10}$ reported that carriers, who were lost for follow-up after the test, reported more distress before testing, compared to carriers who participated in the follow-up. However, in our study, no such differences were found. Unfortunately, we have no information on pre-test psychological distress in partners of test applicants.

The present study showed that sufficient attention should be paid to partners of carriers after predictive testing for HD. Carriers' partners have at least as much psychological distress as carriers, but partners have the tendency to draw back. Professionals need to be aware of the various kinds of grieving and concerns of carriers' partners. They should identify the possible lack of social support of partners and give them the opportunity to express their sorrows and worries and to receive social support. Moreover, attention should be paid to the coping strategies used. Given the variability and complexity of psychological responses and coping strategies after predictive testing, in carriers as well as in their partners, it is not possible to make recommendations that fit for all participants involved. Therefore, a careful exploration of the individuals' subjective appraisal of the situation, their psychological and social resources and their coping strategies should be an essential part of each intervention. In general, carriers and their partners should be helped to use problem-solving and support-seeking strategies, and to abandon passive, ruminating and pessimistic strategies. In order to enhance the individual's sense of competence and personal control over life, it might be useful to discuss complex issues like talking with the children about the disease, guilt feelings towards the children and (future) role changes in the partner relationship. More insight into the psychological complexity will result in more appropriate counselling before and after predictive testing and will enable the tailoring of the counselling to the needs of the test applicants and their family.

\section{Acknowledgements}

We thank the couples who participated in this study. We also express special gratitude to Trees Cloostermans who had a major role in the follow-up counselling.

\section{References}

1 Evers-Kiebooms G, Decruyenaere M: Predictive testing for Huntington's disease: a challenge for persons at risk and for professionals. Patient Educ Counsel 1998; 35: 15-26.

2 Broadstock M, Michie S, Marteau T: Psychological consequences of predictive genetic testing: a systematic review. Eur J Hum Genet 2000; 8: 731-738.

3 Duisterhof M, Trijsburg RW, Niermeijer MF, Roos RAC, Tibben A: Psychological studies in Huntington's disease: making up the balance. J Med Genet 2001; 38: 852-861.
4 Codori AM, Brandt J: Psychological costs and benefits of predictive testing for Huntington's disease. Am J Med Genet 1994; 54: 174-184.

5 Tibben A, Timman R, Bannink EC, Duivenvoorden HJ: Three year follow-up after presymptomatic testing for HD in tested individuals and partners. Health Psych 1997; 16: 20-35.

6 Almqvist EW, Bloch M, Brinkman R, Craufurd D, Hayden M, on behalf of an international HD collaborative group: A worldwide assessment of the frequency of suicide, suicide attempts, or psychiatric hospitalization after predictive testing for HD. Am J Hum Genet 1999; 64: 1293-1304.

7 Almqvist EW, Brinkman RR, Wiggins S, Hayden MR, Canadian Collaborative Study of Predictive Testing: Psychological consequences and predictors of adverse events in the first 5 years after predictive testing for HD. Clin Genet 2003; 64: 300-309.

8 Decruyenaere M, Evers-Kiebooms G, Cloostermans T et al: Psychological distress in the 5-year period after predictive testing for HD. Eur J Hum Genet 2003; 11: 30-38.

9 Codori AM, Slavney PR, Rosenblatt A, Brandt J: Prevalence of major depression 1 year after predictive testing for Huntington's disease. Genet Testing 2004; 8: 114-119.

10 Timman R, Roos R, Maat-Kievit A, Tibben A: Adverse effects of predictive testing for Huntington's disease underestimated: longterm effects 7-10 years after the test. Health Psychol 2004; 23: 189-197.

11 Tibben A, Frets PG, van de Kamp JJ et al: On attitudes and appreciation 6 months after predictive DNA testing for Huntington's disease in the Dutch program. Am J Med Genet 1993; 48: $103-111$.

12 Sobel SK, Cowan DB: Impact of genetic testing for Huntington disease on the family system. Am J Med Genet 2000; 90: 49-59.

13 Quaid KA, Wesson MK: Exploration of the effect of predictive testing for Huntington disease on intimate relationships. Am J Med Genet 1995; 57: 46-51.

14 Heim E: Coping-based intervention strategies. Patient educ counsel 1995; 26: $145-151$.

15 Dekker J, Oomen J: Depression and coping. Eur J Psychat 1999; 13: $183-189$.

16 Plumb JC, Orsillo SM, Luterek JA: A preliminary test of the role of experiential avoidance in post-event functioning. J Behav Therapy Experim Psychiat 2004; 35: 245-257.

17 Decruyenaere M, Evers-Kiebooms G, Boogaerts A et al: Predictive testing for Huntington's disease: risk perception, reasons for testing and psychological profile of test applicants. Genet Counsel 1995; 6: 1-13.

18 Beck AT, Steer RA, Garbin M: Psychometric properties of the Beck Depression Inventory: 25 years of evaluation. Clin Psych Rev 1988; 8: $77-100$.

19 Bouman TK, Luteijn F, Albertnagel FA, van der ploeg FA: Enige ervaringen met de Beck Depression Inventory. Gedrag Tijdsch Psych 1985; 13: 13-24.

20 Spielberger CD, Gorsuch RL, Lushene RE: Manual for the State Trait Anxiety Inventory. Palo Alto: Consulting Psychologists Tests, 1970.

21 van der Ploeg HM, Defares PB, Spielberger CD: Handleiding bij de Zelfbeoordelingsvragenlijst: een Nederlandstalige bewerking van de Spielberger STAI. Lisse: Swets \& Zeitlinger, 1980.

22 Horowitz M, Wilner N, Alvarez W: Impact of event scale: a measure of subjective stress. Psychosom Med 1979; 41: 209-218.

23 Wooldridge EQ, Murray RF: The health orientation scale: a measure of feelings about sickle cell trait. Social biology 1988; 35: $123-136$.

24 Schreurs PJ, van de Willige G, Tellegen B, Brosschot JF: De Utrechtse Coping Lijst. Omgaan met problemen en gebeurtenissen. Lisse: Swets \& Zeitlinger, 1988.

25 Westbrook MT: A classification of coping behavior based on multidimensional scaling of similarity rating. J Clin Psych 1979; 35: 407-410.

26 Decruyenaere M, Evers-Kiebooms G, Cloostermans $\mathrm{T}$ et al: Predictive testing for Huntington's disease: relationship with partners after testing. Clin Genet 2004; 65: 24-31. 
27 Kessler S: Forgotten person in the HD family. Am J Med Genet 1993; 48: 145-150.

28 Evers-Kiebooms G, Swerts A, van den Berghe H: Partners of Huntington patients: implications of the disease and opinions about predictive testing and prenatal diagnosis. Genet counsel 1990; 39: 151-159.

29 Hans MB, Koeppen AH: Huntington's chorea. Its impact on the spouse. J Nerv Ment Disease 1980; 168: 209-214.

30 Sobel SK, Cowan DB: Ambiguous loss and disenfranchised grief: the impact of DNA predictive testing on the family as a system. Fam Process 2003; 42: 47-57.
31 Goldbeck R: Denial in physical illness (review). J Psychosom Res 1997; 43: 575-593.

32 Grover S: The psychological dimension of informed consent: dissonance processes in genetic testing. J Genet Counsel 2003; 12: $389-403$.

33 Festinger L (ed): Conflict, Decision and Dissonance. Stanford University Press: Stanford, CA, USA, 1964.

34 Bloch M, Adam S, Fuller A et al: Diagnosis of Huntington disease: a model for the stages of psychological response based on experience of predictive testing program. Am J Med Genet 1993; 47: $368-374$. 